\title{
Providing Care for Underserved Patients: Periodontists' and Periodontal Residents' Educational Experiences, Attitudes, and Behaviors
}

\author{
Adam J. Garfinkle, ${ }^{*}$ Philip S. Richards, ${ }^{\dagger}$ and Marita R. Inglehart ${ }^{\dagger}$
}

Background: Patients with special health care needs (SHCNs) and patients from underrepresented minority and/or low socioeconomic backgrounds are more likely to have problems accessing oral health care services. The objectives of this study are: 1 ) to explore how well the dental education of periodontists prepared them to treat these underserved patients, 2) to assess related professional attitudes and confidence when treating these patients as well as professional behaviors, and 3) whether educational experiences are related with attitudes, confidence, and behaviors in this context.

Methods: Survey data were collected from a randomly selected sample of 291 members of the American Academy of Periodontology (AAP) and 64 periodontal residents.

Results: Overall, large percentages of residents agreed that their predoctoral and graduate dental educations had prepared them well to treat patients with special needs (predoctoral education: 58\%; clinical graduate education: $45 \%$; and classroom-based graduate education: $37 \%$ ), from different ethnic/racial backgrounds (predoctoral education: 74\%; clinical graduate education: 74\%; and classroom-based graduate education: $60 \%$ ), and on Medicaid (predoctoral education: 60\%; clinical graduate education: 61\%; and classroom-based graduate education: 42\%). Practicing clinicians were least positive about their educations. Students were more positive about treating patients on Medicaid and pro bono cases than practicing clinicians. However, the two groups did not differ in their confidence when treating underserved patients. The quality of predoctoral and graduate educations regarding underserved patients correlates with the attitudes, confidence, and behaviors of providers concerning providing care for these patients.

Conclusions: The findings of this study stress the importance of preparing future periodontists in their predoctoral and graduate programs for providing care for underserved patients such as patients with SHCNs. The better that dental education prepares future periodontists to provide care for underserved patients, the more confident periodontists will be when encountering these patients in their own practices and the more likely they will be to contribute to reducing disparities in oral health care access in the United States by treating these patients. J Periodontol 2010;81:16041612.

\section{KEY WORDS}

Medicaid; minorities; persons with disabliltes; professional education.
I n 2000, the United States (U.S.) Surgeon General's Report on Oral Health ${ }^{1}$ stated that U.S. citizens from economically disadvantaged and/or underrepresented minority backgrounds and/or patients with special health care needs (SHCNs) have disproportionately more periodontal disease compared to the rest of the U.S. population. These problems were further exacerbated by the fact that these patients were more likely to have problems accessing dental care that clearly contributed to increased periodontal disease in these particular patient groups. ${ }^{2-6}$ Underserved patient groups that were spotlighted in the Surgeon General's report make up a substantial proportion of the U.S. population. For example, in $2007, \approx 51.2$ million U.S. citizens had some type of a disability, and $\approx 14.3$ million citizens $>15$ years of age, or $\approx 6 \%$ of the U.S. population, had a mental handicap. ${ }^{7}$ In June 2009, >46 million U.S. citizens were enrolled in the Medicaid

doi: $10.1902 / j o p .2010 .100183$ 
Program. ${ }^{8}$ Over 100 million U.S. citizens, or roughly one-third of the U.S. population, were from historically underrepresented minority backgrounds. ${ }^{9}$ These statistics highlight the fact that a substantial segment of the U.S. population is likely to be at risk for experiencing problems with accessing oral health care services. Therefore, one challenging concern is how access to oral health care for these underserved patients, such as access to periodontal care, could be increased.

Research with general dentists, predoctoral dental students, ${ }^{10-12}$ as well as specialists and residents ${ }^{13}$ showed that the quality of the predoctoral and graduate dental educations of dental care providers was significantly correlated with the attitudes and behaviors of providers concerning treating underserved patients. For example, in a study of general dentists that analyzed which providers were most likely to provide dental care for children (another group of patients with difficulties accessing health care according to the Surgeon General's report ${ }^{1}$ ), Rich et al. ${ }^{11}$ showed that the level of dentists' educational preparedness was significantly correlated with many factors. These factors included: the attitudes of general dentists concerning the treatment of pediatric patients, how well their practice was set up to treat children, how knowledgeable and comfortable their staff were with providing care for children, and the professional behaviors of dentists, such as the types of services they provided for children. ${ }^{11}$ Smith et al. ${ }^{12}$ provided empirical evidence in a study with dental students and general dentists that there was a positive relationship between their self-perceived quality of education regarding treating patients from all segments of society and intentions of students and the actual behaviors of alumni related to providing inclusive care to patients from diverse backgrounds. Dao et al. ${ }^{10}$ focused their efforts on understanding how dental education was related to attitudes and behavior concerning patients with SHCNs and provided extensive evidence that there were significant relationships between the quality of dental education and future professional attitudes and behaviors concerning treating these patients. In 2009, Brown et al. ${ }^{13}$ conducted a study with orthodontists and orthodontic residents and showed that the educational experiences of these specialists with underserved patients and their professional attitudes and behaviors were clearly related to their professional attitudes and behaviors concerning patients with SHCNs and patients on Medicaid. These findings raise the concerns of how well periodontists and periodontal residents feel prepared by their education to treat underserved patients and whether their perceptions of the quality of their predoctoral and/or graduate educations affect their professional behaviors when caring for these patients.
In addition to analyzing how dental education affects the professional behaviors of periodontists, it might also be worthwhile to analyze how education shapes the attitudes of periodontists toward underserved patients. Research ${ }^{14}$ documented that the beliefs of medical providers about human rights and their personal values were significantly related with providing care for underserved patients. For example, research by Mofidi et al. ${ }^{15}$ in dentists affiliated with the National Health Service Corps showed that altruistic motivations were a positive predictor of the number of years the dentists worked with underserved populations in this non-profit organization. Just as positive attitudes increased the likelihood of serving underserved patients, negative attitudes decreased the willingness of dentists to serve underserved patients. For example, Burtner and Dicks ${ }^{16}$ showed that negative attitudes toward patients with special needs affected the willingness of dentists to treat these patients. Research with general dentists also supported the hypothesis that the more positive the attitudes of general dentists were toward treating patients with special needs ${ }^{10}$ and patients on Medicaid and/or from underrepresented minority backgrounds ${ }^{12}$ made it more likely that these providers would provide care for these patients. In consideration of these findings, predoctoral and graduate dental educations might affect the values of students and their confidence in their own skills, which, in turn, might affect professional behavior in this context. Therefore, the present study also explores whether there is a relationship between dental education and the perceptions of periodontists and periodontal residents of their educational experiences and their professional attitudes and levels of confidence concerning treating underserved patients and whether these attitudes and confidence levels are related to the professional behaviors of periodontists.

In summary, given the high percentages of U.S. citizens that have disproportionate amounts of poor oral health while at the same time facing difficulties accessing care, it is worthwhile to reflect on how periodontists relate to these issues. Periodontists are keenly aware of the benefits of periodontal care for their patients and how effectively their care improves oral health and the quality of life of their patients. However, to our knowledge, no study has explored the responses of periodontists to the challenges of providing care for underserved patient populations. Therefore, the objectives of this study are to explore: 1 ) how periodontists and periodontal residents perceive the quality of their predoctoral and graduate educations about underserved patients, and 2) how the quality of this education is related to their professional attitudes, their confidence when providing care for these patients, and 3) their behaviors concerning treating underserved patients. 


\section{MATERIALS AND METHODS}

This study was approved by the Institutional Review Board for the Health Sciences at the University of Michigan.

\section{Respondents}

Survey data were collected from 291 practicing periodontists who were members of the American Academy of Periodontology (AAP) and from 64 periodontal residents who were enrolled in 22 accredited nonmilitary associated periodontal residency programs in the U.S. Of the 291 periodontists, 205 (70\%) of them responded to a mailed survey, and 86 (30\%) periodontists responded to a Web-based survey. All periodontal residents responded to a Web-based survey. Table 1 provides an overview of the background characteristics of the respondents and shows that the majority of the practicing clinicians (84\%) and residents $(63 \%)$ were male, and the practicing clinicians were, on average, 53 years old (SD: 11.5 years).

\section{Procedure}

Data from the practicing periodontists were collected with a survey that was administered by mail in August 2009, and as a Web-based survey in June and July 2009. This survey was mailed to a random sample of 600 active members of the AAP together with a cover letter that explained the study and a stamped return envelope. A random number table was used to ensure randomization. A total of 205 periodontists responded (response rate: $34 \%$ ). Because of financial constraints, no more surveys could be mailed. However, a recruitment e-mail with a link to a Web-based version of the survey was sent to an additional 895 members of the AAP who had been randomly chosen from the 2009 AAP membership directory. A total of 86 periodontists responded to the Web-based survey (response rate: $9.6 \%$ ). Respondents who had received the mailed survey were eliminated from consideration before the respondents for the Web-based survey were selected.

The data from the periodontal residents were collected by sending emails to the postdoctoral periodontal chairs at the 48 university-based periodontal graduate programs as well as the three Veteran Affairs programs in the U.S. These emails described the project and asked the chairs to forward a recruitment e-mail with a link to the survey to their residents. It is unclear how many of these 51 chairs actually forwarded this e-mail and how many residents were in each program. Therefore, a response rate could not be computed. However, 64 residents (mostly second- or third-year residents) from 22 programs responded to the Web-based surveys. Because these 22 programs have different curricula, the residents clearly had different educational experiences.

\section{Materials}

The survey consisted of four parts. Part 1 asked questions about the demographic backgrounds of respondents and the characteristics of their patients. Part 2 focused on assessing the perceptions of respondents about their educational experiences with providing care for the underserved adult groups mentioned in the U.S. Surgeon General's Report on Oral Health. ${ }^{1}$ These questions referred specifically to their education concerning providing care for patients with SHCNs, from historically underrepresented minority backgrounds, and from socioeconomically disadvantaged backgrounds. Questions concerning the education of respondents about patients with SHCNs focused on developmentally disabled patients and patients with special needs in general. Questions concerning socioeconomically disadvantaged patients asked about the respondents' perceptions of their education about treating patients on Medicaid and accepting patients as pro bono patients. Education-related questions were structured so that they assessed the perceptions of respondents about how well their classroom-based, clinical, and community-based education had prepared them for treating these patients. Part 3 included questions about their attitudes concerning these patients and their confidence when treating them. Part 4 focused on professional behavior; residents were asked to indicate their intentions about providing care for these patients in their future professional lives, and practicing clinicians answered questions about their current professional behaviors with regard to providing care for these patients. Most questions were rating-scale questions with five-point answer scales.

\section{Statistical Analyses}

The data were analyzed with a statistical program package. ${ }^{\ddagger}$ Descriptive statistics (e.g., frequencies and means) were computed to describe the responses. The average responses of periodontists and periodontal residents were compared to independent sample $t$ tests. Pearson correlation coefficients were used to determine the relationships among responses.

\section{RESULTS}

Table 1 presents an overview of the background characteristics of the periodontists and periodontal residents who participated in this study. The majority of the respondents were males. The average age of the residents was lower than the average age of the practicing clinicians.

\footnotetext{
‡ SPSS 17.0 Student Version for Windows (SA), Somers, NY.
} 
Table I.

\section{Overview of the Background Variables}

\begin{tabular}{|c|c|c|c|}
\hline Sociodemographic Background & $\begin{array}{l}\text { Graduate Residents } \\
\qquad(n=64)\end{array}$ & $\begin{array}{l}\text { Clinicians } \\
(n=291)\end{array}$ & $P$ \\
\hline Gender (\%) & & & $<0.01$ \\
\hline Male & 63 & 84 & \\
\hline Female & 36 & 16 & \\
\hline Age (years) & & & $<0.01$ \\
\hline Mean & 29 & 53 & \\
\hline SD & 2.9 & 11.5 & \\
\hline Range & 24 to 39 & 30 to 84 & \\
\hline Ethnicity (\%) & & & 0.19 \\
\hline African American & 0 & 2 & \\
\hline Asian American & 13 & 7 & \\
\hline European American & 64 & 77 & \\
\hline American Indian & 0 & I & \\
\hline Hispanic American & 6 & 5 & \\
\hline Biracial & 0 & 1 & \\
\hline Other & 16 & 5 & \\
\hline \multicolumn{4}{|l|}{ Educational/professional background } \\
\hline $\begin{array}{l}\text { Year in graduate school or years of } \\
\text { practice }\end{array}$ & $\begin{array}{c}\text { Year I }(n=9) \\
\text { Year } 2(n=27) \\
\text { Year } 3(n=25) \\
\text { Unreported }(n=3)\end{array}$ & $\begin{array}{c}\text { Mean }=21 \\
S D=11.0 \\
\text { Range }=0 \text { to } 51\end{array}$ & \\
\hline Number of programs & 22 & Not available & \\
\hline
\end{tabular}

\section{Educational Experiences Concerning Underserved Patients}

Table 2 shows that both practicing clinicians and residents felt well prepared by their predoctoral education to treat patients from different ethnic backgrounds (mean scores on a five-point scale with 5 indicating best preparation were 4.07 and 4.08 , respectively) as well as from socioeconomically disadvantaged backgrounds (scores of 4.02 and 4.24, respectively). However, respondents in both groups indicated that they were less well prepared to treat patients with SHCNs (clinicians: 3.24; residents: 3.53 ). In addition, practicing clinicians felt significantly less well prepared to treat patients on Medicaid compared to the residents (3.36 versus 3.80 , respectively; $P=0.012$ ).

The questions concerning the quality of the graduate education of respondents were divided into three groups, namely into questions concerned with the perceptions of respondents about their clinical, classroombased, and community-based graduate educations. Overall, these experiences were less positive compared to the predoctoral experiences of respondents.

The residents perceived their clinical experiences less negatively than the practicing clinicians on four of the five questions. Residents felt better pre- pared than clinicians to treat patients with developmental disabilities (3.02 versus 2.50 , respectively; $P=0.002$ ), with SHCNs (3.18 versus 2.65, respectively; $P=0.003$ ), from different ethnic/racial backgrounds (4.05 versus 3.66, respectively; $P=0.012$ ), and patients on Medicaid (3.66 versus $2.51 ; P<0.001)$. This pattern of less negative responses by residents compared to practicing clinicians was also repeated in the answers to the questions concerning the classroom-based education about underserved patients. Residents felt significantly better prepared by their graduate education to treat patients with SHCNs (2.94 versus 2.46, respectively; $P=0.005)$, with developmental disabilities $(2.77$ versus 2.33 , respectively; $P=$ $0.009)$, patients on Medicaid (3.34 versus 2.27, respectively; $P<0.001)$, and patients as pro bono cases ( 3.02 versus 2.66, respectively; $P=0.04$ ) (Table 2).

Not all residency programs educate their residents in community-based settings. Therefore, before the respondents answered the questions about community-based educational experiences, they indicated whether their graduate program had placed them in a community setting. The majority of the residents (84\%) and practicing clinicians (55\%) reported that they had participated in community-based graduate education. However, these experiences differed in the number of days of community-based education, with residents reporting to have had, on average, 20 days (SD: 29.3 days) of community-based education, and practicing clinicians reporting to have had, on average, 38 days (SD: 69 days) of community-based education. Overall, these community-based experiences were not rated positively. However, there was one exception: practicing clinicians rated their community-based educational experiences concerning treating patients from different ethnic/racial backgrounds positively and even more positively than did the residents (3.40 for residents versus 4.00 for clinicians; $P=0.033$ ). Residents rated their community-based experiences with patients on Medicaid less negatively than did practicing clinicians (3.10 versus $2.54 ; P=0.034$ ) (Table 2 ). 
Table 2.

\section{Average Responses of Students and Clinicians Concerning Educational Experiences About Treating Underserved Patients and the Significance of These Differences}

\begin{tabular}{|c|c|c|c|}
\hline Responses & $\begin{array}{l}\text { Students } \\
\text { (mean [SD]) }\end{array}$ & $\begin{array}{l}\text { Clinicians } \\
\text { (mean [SD]) }\end{array}$ & $P$ \\
\hline \multicolumn{4}{|c|}{ My predoctoral dental education prepared me well to treat* } \\
\hline A. Patients with $\mathrm{SHCNs}$ & $3.53(1.05)$ & $3.24(1.26)$ & 0.133 \\
\hline $\begin{array}{l}\text { B. Patients from different ethnic/racial } \\
\text { backgrounds }\end{array}$ & $4.08(0.89)$ & $4.07(1.00)$ & 0.945 \\
\hline $\begin{array}{l}\text { C. Socioeconomically disadvantaged } \\
\text { patients }\end{array}$ & $4.24(0.88)$ & $4.02(1.06)$ & 0.175 \\
\hline D. Medicaid patients & $3.80(0.92)$ & $3.36(1.16)$ & 0.012 \\
\hline Predoctoral education index ${ }^{\dagger}$ & $3.89(0.79)$ & $3.66(0.89)$ & 0.112 \\
\hline \multicolumn{4}{|c|}{ My clinical graduate education prepared me well to treat patients* } \\
\hline E. With SHCNs & $3.18(1.12)$ & $2.65(1.25)$ & 0.003 \\
\hline F. With developmental disabilities & $3.02(1.11)$ & $2.50(1.22)$ & 0.002 \\
\hline $\begin{array}{l}\text { G. From different ethnic/racial } \\
\text { backgrounds }\end{array}$ & $4.05(1.02)$ & $3.66(1.29)$ & 0.012 \\
\hline H. On Medicaid & $3.66(1.04)$ & $2.51(1.32)$ & $<0.001$ \\
\hline I. As pro bono cases & $3.28(1.09)$ & $3.01(1.39)$ & 0.172 \\
\hline \multicolumn{4}{|c|}{ My classroom-based graduate education prepared me well to treat patients* } \\
\hline J. With SHCNs & $2.94(1.16)$ & $2.46(1.23)$ & 0.005 \\
\hline K. With developmental disabilities & $2.77(1.17)$ & $2.33(1.20)$ & 0.009 \\
\hline $\begin{array}{l}\text { L. From different ethnic/racial } \\
\text { backgrounds }\end{array}$ & $3.84(1.06)$ & $3.80(1.26)$ & 0.791 \\
\hline M. On Medicaid & $3.34(1.06)$ & $2.27(1.19)$ & $<0.001$ \\
\hline N. As pro bono cases & $3.02(1.10)$ & $2.66(1.21)$ & 0.040 \\
\hline Graduate Education Index & $\begin{array}{l}\text { Students } \\
\text { (mean [SD]) }\end{array}$ & $\begin{array}{l}\text { Clinicians } \\
\text { (mean [SD]) }\end{array}$ & $P$ \\
\hline Special needs/Medicaid/pro bono ${ }^{\ddagger}$ & $3.15(0.92)$ & $2.69(0.92)$ & 0.026 \\
\hline Patients from different ethnicities ${ }^{\S}$ & $3.80(1.15)$ & $3.95(0.97)$ & 0.483 \\
\hline \multicolumn{4}{|c|}{ My community-based graduate education prepared me well to treat patients* } \\
\hline With SHCNs & $2.90(0.92)$ & $2.86(1.17)$ & 0.880 \\
\hline With developmental disabilities & $2.84(0.86)$ & $2.73(1.22)$ & 0.645 \\
\hline From different ethnic/racial backgrounds & $3.40(1.30)$ & $4.00(1.20)$ & 0.033 \\
\hline On Medicaid & $3.10(1.16)$ & $2.54(1.32)$ & 0.034 \\
\hline As pro bono cases & $3.20(1.19)$ & $2.86(1.38)$ & 0.207 \\
\hline
\end{tabular}

* Answers ranged from 1 (disagree strongly) to 5 (agree strongly).

† Constructed by averaging respondents' answers to items A through D.

‡ Constructed by averaging respondents' answers to items $\mathrm{E}, \mathrm{F}, \mathrm{H}$, and I as well as $\mathrm{J}, \mathrm{K}, \mathrm{M}$, and $\mathrm{N}$.

$\S$ Constructed by averaging the respondents' answers to items $G$ and $L$.

\section{Attitudes, Confidence, and Professional Behaviors Concerning Underserved Patients}

Table 3 provides an overview of the answers of respondents concerning their professional attitudes, their degrees of confidence, and their behaviors when treating underserved patients. Although attitudes toward treating patients from different ethnic/ racial backgrounds were quite positive (students: 4.33; clinicians: 4.32), attitudes toward providing care for patients with SHCNs (students: 3.41; clinicians: 2.04), and especially attitudes toward patients with developmental disabilities (students: 2.98; clinicians: 2.66) were substantially less positive. Practicing clinicians were most negative toward treating patients on Medicaid (students: 3.15; clinicians: 1.92) (Table 3). A comparison of the average responses of residents versus periodontists showed that the attitudes of residents were more positive than the attitudes of practicing clinicians toward patients with SHCNs, patients with developmental disabilities, patients on Medicaid, and pro bono cases.

The confidence levels when treating patients with special needs and patients with developmental disabilities were slightly positive and did not differ for the two respondent groups. An analysis of the answers concerning the professional behaviors of respondents showed that both groups of providers treated relatively low percentages of patients with SHCNs and developmental disabilities. However, residents were significantly more likely than clinicians to treat patients with SHCNs ( $5 \%$ versus 3\%, respectively; $P<0.001$ ), with developmental disabilities $(2 \%$ versus $1 \%$, respectively; $P=$ 0.038 ), and patients on Medicaid $(33 \%$ versus $2 \%$, respectively; $P<0.001)$ compared to periodontists. Periodontists provided free/pro bono care for $3 \%$ of their patients.

The final objective of this study is to explore whether the perceptions of residents and practicing clinicians regarding their dental education correlated with their attitudes, confidence, and behaviors concerning treating underserved patients. For the purpose of these analyses, a predoctoral education index was constructed by averaging the responses to the four questions concerning the predoctoral dental education of respondents (Table 2); a second index 
Table 3.

\section{Average Responses of Students and Clinicians Concerning Attitudes, Levels of Confidence and Behaviors Concerning Treating Underserved Patients and the Significance of These Differences}

\begin{tabular}{|c|c|c|c|}
\hline Responses & $\begin{array}{l}\text { Students } \\
\text { (mean [SD]) }\end{array}$ & $\begin{array}{l}\text { Clinicians } \\
\text { (mean [SD]) }\end{array}$ & $P$ \\
\hline \multicolumn{4}{|l|}{ Attitudes: I like to treat* } \\
\hline Patients with SHCNs & $3.41(0.99)$ & $2.94(0.96)$ & 0.001 \\
\hline Patients with developmental disabilities & $2.98(1.04)$ & $2.66(1.00)$ & 0.026 \\
\hline Patients from different ethnic/racial backgrounds & $4.33(0.74)$ & $4.32(0.87)$ & 0.920 \\
\hline Patients on Medicaid & $3.15(1.01)$ & $1.92(1.06)$ & $<0.001$ \\
\hline Patients as pro bono cases & $3.61(0.83)$ & $3.09(1.19)$ & 0.001 \\
\hline \multicolumn{4}{|l|}{ Confidence: I am confident treating* } \\
\hline Patients with special needs & $3.51(1.00)$ & $3.48(1.07)$ & 0.886 \\
\hline Patients with developmental disabilities. & $3.32(1.01)$ & $3.26(1.13)$ & 0.674 \\
\hline \multicolumn{4}{|l|}{ Practice question } \\
\hline $\begin{array}{l}\text { My patients are from different ethnic/racial } \\
\text { backgrounds* }\end{array}$ & $4.39(0.73)$ & $4.58(0.80)$ & 0.065 \\
\hline \multicolumn{4}{|l|}{ Professional behavior: average percentage of active } \\
\hline Patients with SHCNs & $5(4.8)$ & $3(6.1)$ & $<0.001$ \\
\hline Patients with developmental disabilities & $2(2.6)$ & I ( 1.4$)$ & 0.038 \\
\hline Patients on Medicaid & $33(28.4)$ & $2(6.9)$ & $<0.001$ \\
\hline Pro bono patients & $4(5.4)$ & $3(9.0)$ & 0.167 \\
\hline
\end{tabular}

* Answers ranged from 1 (disagree strongly) to 5 (agree strongly).

regarding graduate education about patients with special needs/Medicaid/pro bono cases was constructed by averaging the responses concerning the classroom-based and clinical graduate educations about special needs patients, patients with developmental disabilities, patients on Medicaid, and pro bono cases. The community-based responses were not included in these indices because: 1) not all respondents had experienced community-based education, and 2) even if respondents had community-based educational experiences, they differed in the number of days spent in community-based settings. A third index was computed by averaging responses concerning the different types of graduate education about patients from different ethnic/racial backgrounds. Pearson correlation coefficients were computed for respondents from both groups combined to assess the relationships among each of the three indices and attitudinal items, confidence assessments, and behavior responses.

The more positive the respondents were about their predoctoral education, the more positive their attitudes were and the more confident they were when treating patients with special needs and developmental disabilities. The better the respondents evaluated their graduate education about treating special needs, Medicaid, and pro bono patients, the more positive their attitudes were toward these three groups of patients, the more confident they were, and the more likely they were to treat patients with special needs and patients on Medicaid. Finally, the better the respondents evaluated their education about patients from different ethnic/ racial backgrounds, the more positive their attitudes were toward these patients and the more likely they were to agree with the statement, "My patients are from different ethnic/racial backgrounds." Table 4 shows that these correlations indicate contentcongruent relationships between the quality of graduate educational experiences and the professional attitudes confidence levels, and behaviors of respondents. The bolded correlation coefficients in Table 4 show that the quality of education about treating patients from different ethnic/racial backgrounds correlated with the attitudes and behaviors concerning these patients, and the educational experiences concerning treating patients with special needs and from socioeconomically disadvantaged backgrounds were correlated with attitudes, confidence levels, and behaviors concerning treating these patients.

\section{DISCUSSION}

Health care reform in the U.S. is a hotly debated topic. Underlying this debate are the concerns of how unmet health care needs can be met in the U.S. and how access to health care services can be increased. In dentistry, research ${ }^{1}$ documented that disproportionally large amounts of dental disease are found in some specific segments of the U.S. population. Research ${ }^{1}$ also showed that these same patient groups were likely to have unmet oral health care needs and faced limited access to oral health care services, including periodontal health care. This study explored whether educational experiences contributed to this situation. It analyzed how the perceptions of periodontists and periodontal residents regarding their educational experiences related to their professional attitudes, confidence, and behaviors, concerning providing care for 
Table 4.

\section{Correlations Between Educational Experiences and Attitudes, Levels of Confidence, and Professional Behaviors}

\begin{tabular}{|c|c|c|c|}
\hline \multirow[b]{2}{*}{ Attitudes and Behaviors } & \multirow[b]{2}{*}{$\begin{array}{l}\text { Predoctoral } \\
\text { Education }\end{array}$} & \multicolumn{2}{|c|}{ Graduate Education About Patients } \\
\hline & & $\begin{array}{c}\text { With Special } \\
\text { Needs/Medicaid/Pro Bono }\end{array}$ & $\begin{array}{l}\text { From Different } \\
\text { Ethnicities }\end{array}$ \\
\hline \multicolumn{4}{|l|}{ Attitudes: I like to treat* } \\
\hline Patients with special needs & $0.23^{\dagger}$ & $0.32^{\ddagger}$ & 0.14 \\
\hline Patients with developmental disabilities & $0.23^{\dagger}$ & $0.33^{\ddagger}$ & 0.08 \\
\hline $\begin{array}{l}\text { Patients from different ethnic/racial } \\
\text { backgrounds }\end{array}$ & $0.37^{\ddagger}$ & 0.06 & $0.27^{\dagger}$ \\
\hline Patients on Medicaid & $0.17 \S$ & $0.26^{\dagger}$ & -0.11 \\
\hline Patients as pro bono cases & 0.07 & $0.24^{\S}$ & 0.08 \\
\hline \multicolumn{4}{|l|}{ Confidence: I am confident treating* } \\
\hline Patients with special needs & $0.25^{\dagger}$ & $0.30^{\dagger}$ & 0.12 \\
\hline Patients with developmental disabilities & $0.25^{\dagger}$ & $0.24^{\S}$ & 0.03 \\
\hline \multicolumn{4}{|l|}{ Professional behavior: percentage of active } \\
\hline Patients with SHCNs & 0.14 & $0.27^{\S}$ & $0.20 \S$ \\
\hline Patients with developmental disabilities & -0.28 & -0.22 & -0.17 \\
\hline Patients on Medicaid & 0.12 & $0.304^{\dagger}$ & -0.01 \\
\hline Pro bono patients & -0.05 & 0.26 & 0.11 \\
\hline $\begin{array}{l}\text { My patients are from different ethnic/racial } \\
\text { backgrounds* }\end{array}$ & $0.32^{\ddagger}$ & 0.17 & $0.46^{\ddagger}$ \\
\hline
\end{tabular}

* Answers ranged from 1 (disagree strongly) to 5 (agree strongly).

$\dagger \leq 0.01$.

$\neq \leq 0.001$.

$\S \leq 0.05$.

Bold = significant content congruent correlation coefficients

underserved patients such as patients with SHCNs or patients on Medicaid. Past research showed that the predoctoral dental education about underserved patients was a positive predictor for the professional attitudes and behaviors of students and general dentists. ${ }^{10-12,16}$ Most recently, a study ${ }^{13}$ with orthodontists and orthodontic residents also provided evidence that graduate dental education had an effect on the attitudes and behaviors of providers concerning treating patients with SHCNs, patients on Medicaid, and patients from different ethnic/racial backgrounds. This current study focused on this situation by analyzing data from periodontal residents from accredited graduate programs across the country as well as from practicing periodontists who were active members of the AAP.

The first objective was to gain a better understanding of the thoughts of these respondents concerning the quality of their predoctoral education as well as their classroom-based, clinical, and community-based graduate educations about treating patients from underserved patient populations. Three trends were observed in these data. First, overall, responses to the questions concerning the quality of predoctoral education were more positive than responses to the questions about the quality of graduate education. Second, responses of residents were mostly more positive than responses of practicing clinicians concerning their graduate education. Finally, the responses tended to be content specific: education about patients with special needs tended to be more negative, whereas responses concerning educational experiences about treating diverse patients were more positive. These findings were similar to the findings by Brown et al. ${ }^{13}$

These three patterns of responses were largely repeated in the answers to the attitudinal and behavioral questions. In the 21 st century, practicing periodontists in the U.S. seem to embrace the fact that their patients will be from diverse backgrounds. However, attitudes concerning providing care for patients with SHCNs and especially patients with developmental disabilities were substantially less positive, especially among practicing clinicians. The most negative attitudes of practicing clinicians were concerned with treating patients on Medicaid. Because of the poor reimbursement provisions for periodontal care in most U.S. states, this response is not surprising. ${ }^{17-19}$

However, the central objective of this study was to explore whether there was a relationship between the educational experiences of residents and practicing 
clinicians and their professional attitudes, confidence, and behaviors concerning treating underserved patients. Table 4 shows that there were contentcongruent relationships between the educational experiences respondents and their attitudes and confidence. The better respondents felt prepared by their predoctoral dental education, the better their attitudes were concerning the treatment of all underserved groups, and the more confident they were when treating patients with SHCNs. The better respondents felt prepared to treat patients with special needs, patients on Medicaid, and pro bono cases, the better their attitudes were toward providing care for these particular patient groups, and the more confident they were when treating patients with special needs. Finally, the better the respondents evaluated the quality of their graduate education about providing care for diverse patients, the more positive their attitudes were concerning treating patients from different ethnic/racial groups, and the more they agreed with the statement that their patients were from different ethnic/racial backgrounds. These findings are not only consistent with the findings from earlier studies, ${ }^{10-13,20}$ but go beyond the results of these studies. These findings document that residents and providers alike perceive that their dental education about providing care for diverse patients was quite positive and that ethnicity/racerelated attitudes and behaviors were positive as well.

However, the educational experiences concerning treating special needs patients, particularly in graduate programs, were not described as positively. This lack of educational preparedness might well explain the lack of willingness of dentists to provide care for these patients as documented in earlier studies. For example, in 2002, Waldman and Perlman ${ }^{21}$ showed that dentists reported a lack of knowledge about providing care for patients with special needs and a lack of clinical experiences concerning the treatment of these patients during dental school. Although additional non-education related factors, such as concerns about adequate compensation and special arrangements needed when providing care for these patients, might also affect the decisions of dentists to treat special needs patients, ${ }^{21,22}$ it seems crucial to explore the role of dental education in this context. Given that large percentages of patients with mild or moderate challenges could be treated in dental offices, ${ }^{23,24}$ the question arises as to how dentists (and in the context of this study, how periodontists) could be more optimally prepared to provide this much-needed care. If the community of periodontists accepts responsibility for providing this care, graduate periodontal programs need to include educational experiences concerning the care for these patient groups.

This study had three limitations. First, it was not possible to determine the response rate of residents because the respondents had been approached through their program directors, and it is unclear how many program directors actually forwarded a recruitment e-mail to their residents. In future studies that might use this approach, the request could be made to the program directors to copy the primary investigator of the study on the outgoing e-mails to residents so that the actual recruiting patterns can be documented and taken into consideration when interpreting the data. Second, the response rate of periodontists was low. Only $9.6 \%$ of practicing clinicians responded to the Web-based recruitment e-mail. Based on these findings, the Web-based recruitment of these specialists does not seem a viable option when collecting data. However, the response rate to the mailed surveys was considerably better (34.3\%). It seems as if this method of collecting data should be used in the future. Finally, the numbers of respondents were too small to analyze the data to explore whether certain groups of respondents differed from each other such as younger providers versus more established providers or providers facing retirement. Such an analysis could have provided insights into future trends in the profession when older cohorts of practicing clinicians will be replaced with younger cohorts. Future research could address this question.

\section{CONCLUSIONS}

Based on the results of this study, three conclusions can be drawn. First, the perceptions of periodontal residents of their educational experiences about treating underserved patients were more positive than the perceptions of practicing periodontists. Periodontal residents also had more positive attitudes than did practicing clinicians. Second, attitudes and behavior concerning treating patients from different ethnic/racial backgrounds were most positive, which might reflect cultural changes in the U.S. However, attitudes and behavior concerning providing care for patients with SHCNs were less positive. Third, perceptions of educational experiences were correlated with attitudes, levels of confidence, and behaviors concerning treating underserved patients. These relationships were content congruent: perceptions of educational experiences about treating patients from different ethnic/racial backgrounds correlated with attitudes and behaviors concerning this specific group of patients.

If the profession of periodontics wishes to take the initiative to respond to the problems of access to care for underserved patients, a first step may be changing educational practices concerning these underserved patient groups.

\section{ACKNOWLEDGMENTS}

This research was supported by a Summer Research Program grant from the School of Dentistry, 
University of Michigan (to AJG) and by funds from the Department of Periodontics and Oral Medicine, School of Dentistry, University of Michigan. We want to thank Dr. Laurie K. McCauley, chair of the Department of Periodontics and Oral Medicine, School of Dentistry, University of Michigan, for her support. The authors report no conflicts of interest related to this study.

\section{REFERENCES}

1. U.S. Department of Health and Human Services. Oral Health in America: A Report of the Surgeon General. Rockville, MD: U.S. Department of Health and Human Services, National Institute of Dental and Craniofacial Research, National Institutes of Health; 2000.

2. Costello PJ. Dental health status of mentally and physically handicapped children and adults in the Galway Community Care Area of the Western Health Board. J Ir Dent Assoc 1990;36:99-101.

3. Shaw MJ, Shaw L, Foster TD. The oral health in different groups of adults with mental handicaps attending Birmingham (UK) adult training centres. Community Dent Health 1990;7:135-141.

4. Shapira J, Efrat J, Berkey D, Mann J. Dental health profile of a population with mental retardation in Israel. Spec Care Dentist 1998;18:149-155.

5. Shapira J, Stabholz A, Schurr D, Sela MN, Mann J. Caries levels, Streptococcus mutans counts, salivary pH, and periodontal treatment needs of adult Down syndrome patients. Spec Care Dentist 1991;11:248-251.

6. King T, Kapadia D. Oral health status and treatment needs of institutionalized elderly and disadvantaged population in Fiji (1997). Pac Health Dialog 2003;10: 35-40.

7. U.S. Census Bureau. 20th Annniversary of Americans with Disabilities Act: July 26. Available at: http:// www.census.gov/Press-Release/www/releases/archives/ facts_for_features_special_editions/cb10-ff13.html. Accessed March 20, 2010.

8. The Henry J. Kaiser Family Foundation. Monthly Medicaid Enrollment - Kaiser State Health Facts. Available at: http://www.statehealthfacts.org. Accessed March 20, 2010.

9. U.S. Census Press Releases. Minority population tops 100 million. Available at: http://www.census.gov/ Press-Release/www/releases/archives/population/ 010048.html Accessed March 20, 2010.

10. Dao LP, Zwetchkenbaum S, Inglehart MR. General dentists and special needs patients: Does dental education matter? J Dent Educ 2005;69:11071115.

11. Rich JP 3rd, Straffon L, Inglehart MR. General dentists and pediatric dental patients: The role of dental education. J Dent Educ 2006;70:1308-1315.

12. Smith CS, Ester TV, Inglehart MR. Dental education and care for underserved patients: An analysis of students' intentions and alumni behavior. J Dent Educ 2006;70:398-408.

13. Brown BR, Inglehart MR. Orthodontists' and orthodontic residents' education in treating underserved patients: Effects on professional attitudes and behavior. J Dent Educ 2009;73:550-562.

14. Li LB, Williams SD, Scammon DL. Practicing with the urban underserved. A qualitative analysis of motivations, incentives, and disincentives. Arch Fam Med 1995;4:124-133, discussion 134.

15. Mofidi M, Konrad TR, Porterfield DS, Niska R, Wells B. Provision of care to the underserved populations by National Health Service Corps alumni dentists. $J$ Public Health Dent 2002;62:102-108.

16. Burtner AP, Dicks JL. Providing oral health care to individuals with severe disabilities residing in the community: Alternative care delivery systems. Spec Care Dentist 1994;14:188-193.

17. Medical News Today. Medicaid reimbursement for dental care too low, witnesses testify. April 2, 2007. Available at: www.medicalnewstoday.com/ printerfriendlynews.php?newsid=66614. Accessed July 1, 2009.

18. Im JL, Phillips C, Lee J, Beane R. The North Carolina Medicaid program: Participation and perceptions among practicing orthodontists. Am J Orthod Dentofacial Orthop 2007;132(2):144.e15-21.

19. Hughes RJ, Damiano PC, Kanellis MJ, Kuthy R, Slayton R. Dentists' participation and children's use of services in the Indiana dental Medicaid program and SCHIP: Assessing the impact of increased fees and administrative changes. J Am Dent Assoc 2005; 136:517-523.

20. Newacheck PW, Hughes DC, Hung YY, Wong S, Stoddard JJ. The unmet health needs of America's children. Pediatrics 2000;105:989-997.

21. Waldman HB, Perlman SP. Preparing to meet the dental needs of individuals with disabilities. J Dent Educ 2002;66:82-85.

22. Novak KF, Whitehead AW, Close JM, Kaplan AL. Students' perceived importance of diversity exposure and training in dental education. J Dent Educ 2004; 68:355-360.

23. Waldman HB, Perlman SP. Mandating education of dental graduates to provide care to individuals with intellectual and developmental disabilities. Ment Retard 2006;44:184-188.

24. Steinberg BJ. Issues and challenges in special care dentistry. J Dent Educ 2005;69:323-324.

Correspondence: Dr. Marita R. Inglehart, Department of Periodontics and Oral Medicine, School of Dentistry, University of Michigan, Ann Arbor, MI 48109-1078. Fax: 734/763-5503; e-mail: mri@umich.edu.

Submitted March 31, 2010; accepted for publication June 13, 2010. 